\title{
Treatment of Ruptured Abdominal Aortic Aneurysms: State of the Art
}

\section{Tratamento do Aneurisma da Aorta Abdominal Roto: Estado da Arte}

\author{
José OLIVEIRA-PINTO' $1,2,3$, Joel SOUSA ${ }^{1,2,3}$, Armando MANSILHA $\bowtie 1,2,3$
}

Acta Med Port 2018 Apr;31(4):213-218 - https://doi.org/10.20344/amp.10275

\section{ABSTRACT}

Introduction: Endovascular aneurysm repair for ruptured abdominal aortic aneurysm has been increasingly advocated due to shortterm benefits. Most observational studies point towards survival advantage for endovascular aneurysm repair over open repair. However, randomized clinical trials already performed did not support this data. The aim of this review is to compare post-operative outcomes between endovascular aneurysm repair and open surgery for the treatment of ruptured abdominal aortic aneurysms.

Materials and Methods: MEDLINE databases were searched to access outcomes after endovascular aneurysm repair for ruptured abdominal aortic aneurysm and open repair for ruptured abdominal aneurysm repair. All the randomized controlled trials were included. Large and contemporary observational studies were also considered.

Results: Thirty day mortality ranged between $18 \%-53 \%$ for endovascular aneurysm repair for ruptured abdominal aortic aneurysm and between $24 \%$ - 53\% for open repair. Post-operative complications ranged between $33 \%$ - $77 \%$ for endovascular aneurysm repair for ruptured abdominal aortic aneurysm and $37 \%-80 \%$ for open repair. In hospital stay ranged between 8.5 and 14.3 days for endovascular aneurysm repair for ruptured abdominal aortic aneurysm and between 12.2 and 20.5 days for open repair. Intensive care unit days ranged between 1.75 - 4.2 days for endovascular aneurysm repair for ruptured abdominal aortic aneurysm and 2.5 - 6.3 days for open repair.

Discussion: Survival benefit is found for endovascular aneurysm repair for ruptured abdominal aortic aneurysm in most observational studies, but those are not reproduced by randomized controlled trials data. However, endovascular aneurysm repair for ruptured abdominal aortic aneurysm showed less post-operative complications and hospitalization days.

Conclusion: Endovascular aneurysm repair for ruptured abdominal aortic aneurysm should be considered as first line of treatment in centers with expertise and proper facilities.

Keywords: Aneurysm, Ruptured; Aortic Aneurysm, Abdominal; Blood Vessel Prosthesis Implantation; Endovascular Procedures; Surgical Procedures, Operative

\section{RESUMO}

Introdução: O tratamento endovascular do aneurisma da aorta abdominal roto tem sido progressivamente preferido pelos potenciais benefícios de curto-prazo. A maioria dos estudos observacionais revela uma vantagem na sobrevida imediata para o tratamento endovascular do aneurisma da aorta abdominal roto, relativamente à cirurgia convencional. Contudo, os ensaios clínicos randomizados até hoje realizados não suportam estes resultados. Esta revisão tem por objetivo comparar os resultados do tratamento endovascular do aneurisma da aorta abdominal roto com cirurgia convencional no tratamento de aneurismas rotos.

Materiais e Métodos: Bases de dados MEDLINE foram alvo de pesquisa no sentido de obter informação relativamente a resultados de curto prazo após correção de aneurisma roto por tratamento endovascular do aneurisma da aorta abdominal roto ou cirurgia convencional. Todos os ensaios clínicos randomizados foram incluídos. Estudos observacionais relevantes e contemporâneos foram também considerados

Resultados: Mortalidade aos 30 dias variou entre 18\% - 53\% para o tratamento endovascular do aneurisma da aorta abdominal roto e entre $24 \%$ - $53 \%$ para a cirurgia convencional. Complicações pós-operatórias variaram entre $33 \%$ - $77 \%$ para o tratamento endovascular do aneurisma da aorta abdominal roto e entre $37 \%-80 \%$ para a cirurgia convencional. Tempo de internamento variou entre 8,5 e 14,3 dias para o tratamento endovascular do aneurisma da aorta abdominal roto e entre 12,2 e 20,5 para a cirurgia convencional. Número de dias em cuidados intensivos variou entre 1,75 - 4,2 para o tratamento endovascular do aneurisma da aorta abdominal roto e entre 2,5 - 6,3 para a cirurgia convencional.

Discussão: Vantagem na sobrevida é descrita para o tratamento endovascular do aneurisma da aorta abdominal roto nos estudos observacionais, mas estes dados não foram reproduzidos nos ensaios clínicos randomizados realizados. Contudo, o tratamento endovascular do aneurisma da aorta abdominal roto cursa com menos complicações pós-operatórias e dias de internamento.

Conclusão: $O$ tratamento endovascular do aneurisma da aorta abdominal roto deve ser considerado como primeira linha de tratamento em instituições de elevada experiência e com infra-estruturas adequadas.

Palavras-chave: Aneurisma da Aorta Abdominal; Aneurisma Roto; Procedimentos Cirúrgicos Operatórios; Procedimentos Endovasculares

\section{INTRODUCTION}

Ruptured abdominal aortic aneurysm (rAAA) is a frequently lethal condition, with acute mortality reaching up to $80 \%$. In the United States, rAAA represent the cause

for $4 \%-5 \%$ of sudden deaths. ${ }^{1}$ Patients with rAAA usually present shooting abdominal pain with pulsatile abdominal mass. Lumbar back pain, hypotension and circulatory shock

1. Departamento de Angiologia e Cirurgia Vascular. Centro Hospitalar de São João. Porto. Portugal.

2. Departamento de Cirurgia e Fisiologia. Faculdade de Medicina. Universidade do Porto. Porto. Portugal.

3. Serviço de Angiologia e Cirurgia Vascular. Hospital CUF Porto. Porto. Portugal.

$\triangle$ Autor correspondente: Armando Mansilha. vascular.mansilha@gmail.com

Recebido: 22 de janeiro de 2018 - Aceite: 11 de abril de 2018 | Copyright ( O Ordem dos Médicos 2018 
often arise. Only $50 \%$ of rAAA patients reach the hospital alive and between this group, up to $50 \%$ do not survive to surgical repair. ${ }^{2,3}$ As r-AAA patients surviving in-hospital stay have similar long-term survival when compared to electively treated patients ${ }^{4,5}$ in-hospital, survival is vital for the prognosis of these patients.

In the elective setting, endovascular aneurysm repair (EVAR) is the preferred modality for the management of $A A A$ as a less invasive alternative to open surgical repair (OR), with lower peri-operative mortality. ${ }^{6-9}$ The increasing experience with EVAR for intact aneurysms allied to a new generation of devices spread its applicability to emergency situations as well. However, the acceptance of EVAR for treatment of rAAA ( $r$-EVAR) has faced some obstacles. Despite many observational studies showing short-term survival benefit for endovascular repair of rAAA patients, this data was not confirmed by the results of landmark randomized clinical trials (RCT's). ${ }^{10-15}$

Still, device-related refinements, operator expertise and institutional suited logistics led to progressively better results of the endovascular approach. Consequently, in this recent era many centers have adopted r-EVAR as preferred modality.

This review outlines the results of the major studies comparing EVAR to OR for rAAA and gives a glance on futures perspectives regarding the treatment of this condition.

\section{MATERIALS AND METHODS}

A literature search was performed to identify studies presenting results of standard EVAR for r-AAA as well as studies comparing outcomes between r-EVAR and OR. The search was performed using MEDLINE and studies published between January 2008 and June 2017 were included. All landmark r-EVAR RCTs and most relevant observational studies were included. Studies including fenestrated grafts, chimney procedures or other 'off the shelf' procedures were not included. Observational studies were included if period of inclusion occurred after 2005 with at least 100 EVAR procedures performed. Only studies in English language were included.

\section{Endpoints}

Thirty-day mortality was the primary endpoint. Secondary endpoints included immediate post-operative complications, hospitalization and ICU days.

\section{RESULTS}

Eight studies were included: 4 RCT and 4 observational studies (national registries), including 21293 patients (5319 EVAR and 15975 OR). Data regarding primary and secondary endpoints of the included studies is summarized in Table 1.

\section{Landmark randomized clinical trials}

Four main RCTs comparing outcomes between OR vs. EVAR for rAAA were found: Notthingham Trial, ${ }^{16}$ AJAX trial, ${ }^{13}$ ECAR trial ${ }^{14}$ and IMPROVE trial. ${ }^{15}$ In the first three trials patients were anatomically selected, while the fourth represents a pragmatic clinical trial, as patients were randomized before performing pre-operative CT scan.

\section{Nottingham trial}

This was the first single-center prospective randomized trial comparing EVAR to OR in patients with rAAA. Between September 2002 and December 2004, 103 rAAA patients were admitted, although only 32 patients were included for randomization. Consequently this study was interrupted due to lack of power. All patients in the r-EVAR group received a two-piece aorto-uni-iliac stent-graft made with Gianturco stents with an uncovered suprarenal component. Primary endpoint was 30-day mortality and secondary endpoints were operative complications, hospital stay and time between surgery and diagnosis. No significant differences were found in this study regarding 30-day mortality (53\% for EVAR and $53 \%$ for OR). In the EVAR group, $77 \%$ of patients had moderate or severe complications compared with $80 \%$ in the OAR group. The median total hospital stay in the EVAR group was 10 days (range 6 - 28) compared with 12 in OAR (range 4 - 52). More patients in the EVAR group suffered severe renal complications (6 (55\%) versus $1(8 \%)$ in $\mathrm{OA} ; p=0.02)$. Major conclusions emphasized the possibility to perform a RCT comparing EVAR versus open repair for rAAA and that pre-operative CT scan does not delay the treatment. ${ }^{16}$

\section{Ajax trial}

In the AJAX trial all the patients in Amsterdam region with rAAA who were eligible for endovascular and conventional surgery were included. Inclusion occurred between April 2004 and February 2011. A total of 520 patients with clinical suspicion of rAAA were identified. CT scan confirmed rAAA in 365 patients and, after exclusion due to anatomy or other factors, 116 patients were included (57 r-EVAR and 59 OR). Talent uni-iliac stent-graft (Medtornic AVE Europe) was initially used and then replaced by Endurant aorto-uni-iliac graft (Medtronic BV, Heerlen).

Similar 30-day (EVAR 21\% vs OR 25\%, $p=0.66$ ) and 6 -month mortality (EVAR $28 \%$ vs OR $31 \%$; $p=0.84$ ) were the main findings. Nineteen patients $(33 \%)$ in the r-EVAR groups had severe complications (cardiac, bowel ischemia, reinterventions, stroke, amputation and cord ischemia) when compared to 22 patients (37\%) in the OR group ( $p=$ 0.71). Hospitalization days (9 EVAR vs 13 OR; $p=0.57$ ) as well as ICU stay (42 hours EVAR vs 60 hours OR, $p=0.24$ ) did not significantly differ between groups. ${ }^{13}$

\section{ECAR trial}

In the ECAR trial, 107 patients (56-r-EVAR and 51OR) were recruited between January 2008 and January 2013. Most commonly used grafts were: Zenith (Cook Medical, Bloomington, IN, USA) and Talent (Medtronic, Minneapolis, MN, USA) aorto-uni-iliac devices, or Excluder (WL Gore, Newark, DE, USA), Zenith TriFab (Cook Medical, 
Bloomington, IN, USA), and Talent (Medtronic) bifurcated devices.

Thirty-day (18\% EVAR and $24 \%$ OR) mortality was not statistically different between groups ${ }^{14}$. r-EVAR was associated with lower severe complications, although not statistically significant (44.6\% EVAR vs $54.9 \%$ OR; $p=$ $0.291)$, lower respiratory support time (59.3 hours vs 180.3 hours; $p=0.007)$, less pulmonary complications $(15.4 \%$ vs $41.5 \%$, respectively; $p=0.050$ ) and blood units required (6.8 vs 10.9 , respectively; $p=0.020$ ). Intensive care unit (ICU) stay was also shorter in the EVAR group ( 7 days vs 11.9 days, respectively; $p=0.010$ ). Finally, hospitalization days (14.3 EVAR vs 17.1 OR; $p=0.208$ ) and costs per admission were also reduced in the r-EVAR group (€7087.5 $v s € 9329.4)$.

\section{IMPROVE Trial}

The fourth and the largest trial was the IMPROVE. Six hundred and thirteen patients were recruited from 29 high volume centers in the United Kingdom and 1 in Canada (316 EVAR and 297 OR).

Contrarily to the three previous trials, patients were randomized at the time of diagnosis, often before CTA to ascertain suitability for endovascular repair. Thirty-day mortality (35\% EVAR and 37\% OR; $p=0.62$ ) was not different between groups. EVAR showed a trend towards better outcome in the elderly and seriously ill patients. ${ }^{15}$ Similarly to the ECAR trial r-EVAR group shorter stay in the ICU units (4.2 vs 6.3 days) and in the hospital (9.8 vs 12.2 days) and more patients in this group were directly discharged home $(94 \%$ vs $77 \% ; p<0.001)$.

\section{Relevant observational studies}

In this section some important and contemporary administrative registries are presented.

In 2009 Giles et al published data from the American College of Surgeons National Surgical Quality Improvement Program (NSQIP) database including patients undergoing rAAA repair from 2005 to 2007 ( $n=567: 121$ EVAR and 446 OR). After adjusting for preoperative comorbidities and all preoperative hemodynamic variables, mortality after open repair was greater than after EVAR (OR 1.9, 95\% Cl 1.1 to $3.2 ; p<0.05)$. Overall postoperative complications were greater after open repair $(62 \%$ vs $47 \% ; p<0.01)$. Patients undergoing $\mathrm{OR}$ had higher need for prolonged ventilation (> 24 hours): $44 \%$ vs $24 \% ; p<0.001$. No differences on overall reinterventions occurring within the first 30 days were noticed (21\% EVAR vs $24 \%$ OR; $p=0.43$ ). Graft failure requiring reintervention was higher after EVAR $(4 \%$ vs $1 \% ; p<0.05)$ while wound dehiscence $(0 \%$ vs $4 \% ; p<$ $0.05)$ was higher for OR. ${ }^{17}$

Park et al published in 2013 data from the Nationwide Inpatient Sample (NIS) from 2005 to 2009: 12761 (77.1\%) underwent OSR and 3796 (22.9\%) underwent EVAR. ${ }^{18}$ Despite the generally adverse risk profile of the EVAR patients, univariate analysis demonstrated that RAAA patients treated by EVAR were less likely to die (odds ratio [OR] $0.54 ; p<0.001$ ) or experience postoperative complications (OR $0.51 ; p<0.001$ ) than patients who underwent OSR. Besides, OR patients had more mesenteric ischemia $(6.87 \%$ vs $2.94 \% ; p=<0.0001)$, more reinterventions due to bleeding $(5.45 \%$ vs $1.92 \%$; $p$ $=0.0002)$ or limb ischemia (9.44\% vs 4.69\%; $p=0.0001)$. EVAR patients had a shorter length of stay (9.91 vs 13.0 days; $p<0.0001$ ) and were more likely to be discharged

Table 1 - Results of comparative studies between EVAR and OR for the treatment of rAAA

\begin{tabular}{|c|c|c|c|c|c|c|}
\hline Study & & $\mathbf{n}$ & $\begin{array}{c}\text { 30-day mortality } \\
(\%)\end{array}$ & $\begin{array}{c}\text { Post-operative } \\
\text { complications (\%) }\end{array}$ & $\begin{array}{l}\text { Hospitalization } \\
\text { days }\end{array}$ & $\begin{array}{l}\text { ICU } \\
\text { days }\end{array}$ \\
\hline \multirow{2}{*}{ Notthingham trial ${ }^{15}$} & EVAR & 15 & 53 & 77 & 10 & NS \\
\hline & OR & 17 & 53 & 80 & 12 & NS \\
\hline \multirow{2}{*}{ AJAX trial ${ }^{12}$} & EVAR & 57 & 21 & 33 & 9 & 1.75 \\
\hline & OR & 59 & 25 & 37 & 13 & 2.5 \\
\hline \multirow{2}{*}{ ECAR trial ${ }^{13}$} & EVAR & 56 & 18 & 44.6 & 14.3 & 7 \\
\hline & OR & 51 & 24 & 54.9 & 17.1 & 11.9 \\
\hline \multirow{2}{*}{ IMPROVE trial' ${ }^{14}$} & EVAR & 316 & 35 & NS & 9.8 & 4.2 \\
\hline & OR & 297 & 37 & NS & 12.2 & 6.3 \\
\hline \multirow{2}{*}{$\begin{array}{l}\text { Giles et al, } \\
2009^{16}\end{array}$} & EVAR & 121 & 24 & 47 & 7 & NS \\
\hline & OR & 446 & 36 & 62 & 10 & NS \\
\hline \multirow{2}{*}{$\begin{array}{l}\text { Park et al, } \\
2013^{17}\end{array}$} & EVAR & 3796 & 27.38 & NS & 9.91 & NS \\
\hline & OR & 12761 & 40.96 & NS & 13 & NS \\
\hline \multirow{2}{*}{$\begin{array}{l}\text { Speicher et al, } \\
2014^{18}\end{array}$} & EVAR & 614 & 26.2 & 64.2 & 6 & NS \\
\hline & OR & 1383 & 38.5 & 73.1 & 10 & NS \\
\hline \multirow{2}{*}{$\begin{array}{l}\text { Gunnarsson et al, } \\
2016^{19}\end{array}$} & EVAR & 343 & 21.6 & NS & NS & NS \\
\hline & OR & 961 & 29.6 & NS & NS & NS \\
\hline
\end{tabular}

EVAR: endovascular aneurysm repair; ICU: intensive care unit; n: number of patients included in the study; NS: not stated; OR: open repair 
home than were survivors of OSR $(33.9 \%$ vs $18.6 \%$; $p<$ 0.0001). On multivariable analysis, correcting for hospital type, patient demographics, and preoperative comorbid conditions confirmed the benefit of EVAR over OSR in reducing both mortality $(\mathrm{OR}=0.535 ; 95 \% \mathrm{Cl}, 0.395-0.724)$ and complication rates $(\mathrm{OR}=0.492 ; 95 \% \mathrm{Cl}, 0.380-0.636)$ for patients with RAAA. ${ }^{18}$

From 2005 - 2011 data from National Surgical Quality Improvement Project (NSQIP) Participant User File were used to identify patients with rAAA undergoing open $r$ EVAR. This study included 1997 patients: 1383 (69.3\%) patients underwent an open procedure and $614(30.7 \%)$ patients underwent EVAR. The primary outcome measures for our analysis were 30-day postoperative mortality, operative mortality, 30-day overall complication rate, and early return to the operating room. After adjusting for potential confounders, higher 30-day (OR 1.7; Cl 95\% [1.23 - 2.35]), operative mortality (OR 2.06; Cl 95\% [1.23 - 3.46]) or postoperative major complications (OR 2.15; Cl 95\% [1.61 2.88]) was found for OR. ${ }^{19}$

The results of the SweedVasc registry comparing outcomes between r-EVAR and OR were recently published. Thirteen hundred and four patients were operated in 29 centers (343 EVAR and 961 OR). Analyzing the outcome based on operative technique EVAR seems to present with lower 30 -day mortality compared to OR $(21.6 \%$ vs $29.6 \%$; $p$ $<0.01)$. In this study primary EVAR centers were compared to primary OR centers. Two hundred and thirty six patients were operated among three primary EVAR centers (pEVARc - 74.6\% EVAR) were compared to 1068 patients operated among 26 OR centers (pORc - 15.6\% EVAR). When comparing these two type of centers, there was no difference in mortality rates between them at 30 days (28\% pEVARc vs $27.4 \%$ pORc; $p=0.87$ ).

Mortality was lower for patients treated with EVAR compared with open repair, both at pEVARc and pORc. ${ }^{20}$ Perioperative bleeding $>5 \mathrm{~L}$ was higher for OR group (14.9 vs 29.5; $p$ <.01) while abdominal compartment syndrome requiring laparotomy was higher for EVAR $(9.5 \%$ vs $5.1 \%$; $p=0.03$.

\section{DISCUSSION}

EVAR is increasingly preferred for rAAA repair, and many centers currently adopted this approach as first line of treatment. Despite many observational studies point favorable outcomes for EVAR when compared to OR, these were not reproduced in the major RCTs. 13-15,17-20

Intuitively, the low-invasive profile makes EVAR particularly appealing for rAAA patients: treatment under local anesthesia with lower associated hypotension are more suitable for bleeding patients. Additionally, there is a reduced procedural risk for elderly comorbid patients, usually not considered for open repair. On the other hand, the need for pre-operative CT evaluation might bring an unacceptable delay in the treatment and many centers are still not equipped with specialized facilities and human resources capable of handling EVAR in emergent situations.
Then, although some reports claim excellent results with this technique, the superiority over OR is still under debate.

There is contradiction between RCTs and observational/ national registries results. While no differences on inhospital mortality was found on the first, all the four observational studies included presented lower in-hospital mortality for EVAR. ${ }^{13-17,19,20}$ Additionally, lower post-operative complications and shorter stay is also reported for EVAR both in RCT and administrative registries. ${ }^{15-19}$

For this reason, it is difficult to draw definite conclusions. This inconsistency might be explained by selection bias more likely to occur in retrospective studies as most operators select patients both for EVAR or OR based on aortic morphology and hemodynamic stability. As such, it is likely that patients with more stable hemodynamic condition might be candidate for EVAR justifying better outcomes compared to OR where the more comorbid and unstable patients fit. A recent meta-analysis addressed this topic and concluded that that risk of bias was clearly higher for observational studies when compared to RCT. ${ }^{21}$ Still, many flaws may also be pointed to RCTs conclusions. The Nottingham trial was stopped because it was underpowered. The AJAX and ECAR trial randomized a small proportion of the total screened patients (116/520 and 107/372, respectively). In these, both RCTs hypotensive and unstable rAAA patients were not offered EVAR and were treated with open repair or underwent no treatment. This cohort was exactly the one that would most benefit from EVAR approach. As such, these exclusions might have hidden potential survival advantages for EVAR. Besides, only aorto-uni-iliac endoprosthesis were used in the AJAX trial, not representative of current practice.

The largest RCT was the IMPROVE trial. Six hundred and thirteen patients were randomized from 30 centers. Thirty-day mortality was not different between groups. As the randomization was performed before CT scan, 112 patients initially randomized for EVAR group had anatomies non-suitable for endovascular approach and ended up operated by open approach. On the OR group only 227 of the 290 really underwent OR. Furthermore, 33 patients in the endovascular strategy after CT imaging were found to have another diagnosis and eight patients had symptomatic but not rAAA. In the OR group 22 patients ultimately proved to have another diagnosis and 14 had symptomatic but not rAAA.

The 30-day mortality for patients who actually underwent EVAR was $24.7 \%$ (46 of 186) and in those who actually underwent OR was $38.1 \%$ (128 of 336; $p=0.06$ ). The 3 -year results of the IMPROVE trial gives a strong trend towards lower mortality in the EVAR group. ${ }^{22}$

The observational studies included were national registries with at least 100 patients treated with EVAR included after 2005. Data from the US and Sweden registries show lower mortality rates for EVAR when compared to OR. ${ }^{17,19,20}$ These studies provide results from a large number of patients, deriving from multiple vascular centers, reflecting daily practice over a long time period nationwide. Still, detailed patient characteristics which are 
essential elements for direct comparison between EVAR and OR are scarcely available. The completeness and accuracy of the data is not as robust as data collected in prospective studies and independently reviewed. There are a number of important data known to be associated with mortality after RAAA that not obtainable, such as presence of preoperative shock, loss of consciousness or acute renal failure. Additionally, pre-operative anatomical data is not provided in any of the observational studies which is paramount for the EVAR eligibility. Finally, ICD codification can also be questioned.

Despite less prone to selection bias, the above mentioned structural RCT drawbacks also limit definite conclusions. As rAAA represent an emergent and life-saving condition, the procedure selection is conditioned by the anatomy, logistics and operator experience. Additionally, many of these patients require open conversion during the procedure. This limits the possibility to obtain clean conclusions about the best method of repair even minimizing selection bias. Although no differences in mortality were shown, shorter periods in ICU were reported ${ }^{14,15}$ as well as fewer respiratory complications and hospital costs. ${ }^{14}$ This means that despite no survival benefit presented on the trials less morbidity seems to arise with EVAR.

\section{CONCLUSIONS}

EVAR has been assuming an increasingly more prominent role for rAAA treatment. Most observational studies and administrative registries show a benefit on short-term survival for EVAR, the most influential step for

\section{REFERENCES}

1. Schermerhorn M. A 66-year-old man with an abdominal aortic aneurysm: review of screening and treatment. JAMA. 2009;302:2015-22.

2. Harris LM, Faggioli GL, Fiedler R, Curl GR, Ricotta JJ. Ruptured abdominal aortic aneurysms: factors affecting mortality rates. $\mathrm{J}$ Vasc Surg. 1991;14:812-8.

3. Farhan-Alanie OM, Ahmed Z, Stuart W. Vertebral erosion resulting from a 'non-ruptured' abdominal aortic aneurysm: case report and literature review. Scott Med J. 2012;57:182.

4. Mani K, Bjorck M, Lundkvist J, Wanhainen A. Improved long-term survival after abdominal aortic aneurysm repair. Circulation. 2009;120:201-11.

5. Bastos Goncalves F, Ultee KH, Hoeks SE, Stolker RJ, Verhagen HJ. Life expectancy and causes of death after repair of intact and ruptured abdominal aortic aneurysms. J Vasc Surg. 2016;63:610-6.

6. Greenhalgh RM, Brown LC, Kwong GP, Powell JT, Thompson SG. Comparison of endovascular aneurysm repair with open repair in patients with abdominal aortic aneurysm (EVAR trial 1), 30-day operative mortality results: randomised controlled trial. Lancet. 2004;364:843-8.

7. Lederle FA, Freischlag JA, Kyriakides TC, Padberg FT Jr, Matsumura JS, Kohler TR, et al. Outcomes following endovascular vs open repair of abdominal aortic aneurysm: a randomized trial. JAMA. 2009;302:153542.

8. Sousa J, Brandao D, Barreto P, Ferreira J, Almeida Lopes J, Mansilha A. Tratamento endovascular do aneurisma da aorta abdominal por via percutânea e anestesia local - one day surgery. Acta Med Port. 2016;29:381-8.

9. Prinssen M, Verhoeven EL, Buth J, Cuypers PW, van Sambeek $\mathrm{MR}$, Balm R, et al. A randomized trial comparing conventional and endovascular repair of abdominal aortic aneurysms. N Engl J Med. 2004;351:1607-18.

10. Mayer D, Aeschbacher S, Pfammatter T, Veith FJ, Norgren L, Magnuson $A$, et al. Complete replacement of open repair for ruptured abdominal aortic aneurysms by endovascular aneurysm repair: a two-center 14year experience. Ann Surg. 2012;256:688-95. improving vital prognosis of r-AAA patients. These were not confirmed by RCTs results, probably reflecting the small dimension and design particularities of the later. Inhospital morbidity seems to be lower in the r-EVAR group transversally to all the studies.

The rapid technology development, growing surgical experience allied to duly equipped facilities probably makes the contemporary case series better then found in most studies.

Whenever anatomical and logistically suitable, EVAR should be considered as first option for rAAA repair.

\section{PROTECTION OF HUMANS AND ANIMALS}

The authors declare that the procedures were followed according to the regulations established by the Clinical Research and Ethics Committee and to the Helsinki Declaration of the World Medical Association.

\section{DATA CONFIDENTIALITY}

The authors declare having followed the protocols in use at their working center regarding patients' data publication. Patient consent obtained.

\section{CONFLICTS OF INTEREST}

All authors report no conflict of interest.

\section{FUNDING SOURCES}

This research received no specific grant from any funding agency in the public, commercial, or not-for-profit sectors.

11. Veith FJ, Lachat M, Mayer D, Malina M, Holst J, Mehta M, et al. Collected world and single center experience with endovascular treatment of ruptured abdominal aortic aneurysms. Ann Surg. 2009;250:818-24.

12. von Meijenfeldt GC, Ultee KH, Eefting D, Hoeks SE, ten Raa S, Rouwet $\mathrm{EV}$, et al. Differences in mortality, risk factors, and complications after open and endovascular repair of ruptured abdominal aortic aneurysms. Eur J Vasc Endovasc Surg. 2014;47:479-86.

13. Reimerink JJ, Hoornweg LL, Vahl AC, Wisselink W, van den Broek TA, Legemate DA, et al. Endovascular repair versus open repair of ruptured abdominal aortic aneurysms: a multicenter randomized controlled trial. Ann Surg. 2013;258:248-56.

14. Desgranges $P$, Kobeiter H, Katsahian S, Bouffi M, Gouny P, Favre JP, et al. Editor's choice - ECAR (endovasculaire ou chirurgie dans les anevrysmes aorto-iliaques rompus): a French randomized controlled trial of endovascular versus open surgical repair of ruptured aorto-iliac aneurysms. Eur J Vasc Endovasc Surg. 2015;50:303-10.

15. IMPROVE Trial Investigators, Powell JT, Sweeting MJ, Thompson MM, Ashleigh R, Bell R, et al. Endovascular or open repair strategy for ruptured abdominal aortic aneurysm: 30 day outcomes from IMPROVE randomised trial. BMJ. 2014;348:f7661.

16. Hinchliffe RJ, Bruijstens L, MacSweeney ST, Braithwaite BD. A randomised trial of endovascular and open surgery for ruptured abdominal aortic aneurysm - results of a pilot study and lessons learned for future studies. Eur J Vasc Endovasc Surg. 2006;32:506-13.

17. Giles KA, Pomposelli FB, Hamdan AD, Wyers MC, Schermerhorn ML Comparison of open and endovascular repair of ruptured abdominal aortic aneurysms from the ACS-NSQIP 2005-07. J Eur J Vasc Endovasc Surg. 2009;16:365-72.

18. Park BD, Azefor N, Huang CC, Ricotta JJ. Trends in treatment of ruptured abdominal aortic aneurysm: impact of endovascular repair and implications for future care. J Am Coll Surg. 2013;216:745-54.

19. Speicher PJ, Barbas AS, Mureebe L. Open versus endovascular repair of ruptured abdominal aortic aneurysms. Ann Vasc Surg. 2014;28:1249- 
57.

20. Gunnarsson K, Wanhainen A, Djavani Gidlund K, Bjorck M, Mani $\mathrm{K}$. Endovascular versus open repair as primary strategy for ruptured abdominal aortic aneurysm: a national population-based study. J Eur J Vasc Endovasc Surg. 2016:51:22-8.

21. van Beek SC, Conijn AP, Koelemay MJ, Balm R. Editor's choice - endovascular aneurysm repair versus open repair for patients with a ruptured abdominal aortic aneurysm: a systematic review and meta-analysis of short-term survival. J Eur J Vasc Endovasc Surg. 2014;47:593-602.

22. Powell JT. Three-year outcomes of the IMPROVE trial for ruptured abdominal aortic aneurysm. J Vasc Surg. 2017. 